Copyright (C 2014 IEEE. Personal use of this material is permitted. Permission from IEEE must be obtained for all other uses, in any current or future media, including reprinting/republishing this material for advertising or promotional purposes, creating new collective works, for resale or redistribution to servers or lists, or reuse of any copyrighted component of this work in other works. 


\section{Integration of Wind Energy Conversion System with Microgrid and Utility}

\author{
Yuanyuan Fan, Megha Goyal \\ Department of Electrical and Computer Engineering \\ Curtin University, Bentley, WA
}

\author{
Arindam Ghosh, Farhad Shahnia \\ Department of Electrical and Computer Engineering \\ Curtin University, Bentley, WA
}

\begin{abstract}
An integration of a Permanent Magnetic Synchronous Generator (PMSG) based Wind Energy Conversion System (WECS) into a microgrid is discussed in this paper. A back-to-back Voltage Source Converter (VSC) is employed for the power conversion from the PMSG to the AC grid. The Sinusoidal Pulse Width Modulation (SPWM) technique is adopted for the Wind-side Converter (WSC), while for the Gridside Converter (GSC), Space Vector Pulse Width Modulation (SVPWM) is applied. A Maximum Power Point Track (MPPT) control scheme called the Optimal Power Control (OPC) is used for the WSC to draw the maximum power from wind energy. The DC voltage of the back-to-back converter is controlled by the GSC. The microgrid contains a microturbine and a diesel generator, along with loads. The power flow from the WECS to the microgrid is controlled through another back-to-back converter. Four different cases are studied to validate the performance of the WECS integration with the microgrid system.
\end{abstract}

Keywords-PMSG; WECS; WSC; GSC; PWM; MPPT; OPC; microgird

\section{INTRODUCTION}

Consuming of traditional fossil fuels is becoming an increasingly serious problem for the protection of environment. Air pollution in some developing nations and/or cities has already affected people's health directly. Carbon emission which causes global warming is another problem that cannot be ignored. Because of the deleterious effects of fossil fuels vis-àvis environment and health, the exploitation of renewable energy and distributed generation is attracting more interest worldwide. Among various clean energies, wind energy stands out for its relatively cheaper cost compared to other renewable sources [1-2]. Offshore wind energy is drawing much attention and has been recognized as one of the most promising energy choices due to its enormous resources. Compared to Europe, where big strides have been made in this direction, offshore wind installation is nonexistent in Australia, even though she has excellent offshore wind resources by world standards. Some potential sites in Australia have been identified by researchers where offshore wind power generation may be feasible in the future.

This research deals with Permanent Magnetic Synchronous Generator (PMSG) Wind Energy Conversion System (WECS), which is a variable speed wind generator. The specialty of PMSGs is that the excitation is provided by permanent magnets instead of dc power supply. PMSGs are not the most popular wind generators yet in today's market, but their advantages have made them the most promising ones. First, a full-capacity power converter connected to the PMSG can process all the generated power, therefore the performance of the wind energy system is greatly enhanced compared with the Doubly Fed Induction Generator (DFIG). Second, with the use of the power converter, the generator is fully decoupled from the grid so their control systems are decoupled. Third, PMSGs can be manufactured in small sizes because of their large air gaps and reduced flux linkage. Fourth, the PMSG wind energy system can operate without a gearbox due to the use of low-speed synchronous generators with large number of poles [3]-[7].

According to the commercially used full-capacity power converter operated wind energy conversion systems, the most common converter topology for PMSGs is back-to-back Voltage Source Converters (VSC), back-to-back Neutral Point Clamped (NPC) converters [3] and diode rectifier with DC/DC boost converter and inverter [8]. The topology with a diode rectifier and a boost converter simplified the control and reduced the cost of the system, but the generator torque waveform contains ripples [4]. The NPC converter topology is primarily employed in medium voltage. However, the most frequently used power converter topology is the back-to-back VSC, which is applied in this paper.

Also in this paper, MPPT generator control is realized by using the optimal power control (OPC) scheme to the Windside Converter (WSC) through SPWM technique. For the Gridside Converter (GSC) control, SVPWM technique is applied to maintain the DC voltage to a constant value. The PMSG is then connected with an infinite bus and a microgrid [9]. An integration scheme of WECS with the microgrid and utility is proposed. The microgrid is connected with the WECS and utility through another back-to-back converter. When several microgrids are connected to a utility supply at several places, they need to be electrically isolated so that they can operate in islanded mode, when required. Otherwise, they become a part of a larger distribution system, which defeats the purpose of a microgrid. The back-to-back converters isolate the microgrid from the utility. They can provide isolation and controlled power transfer. The expected control outcomes of the proposed system are validated using the software PSCAD/EMTDC.

\section{SYSTEM STRUCTURE}

A simple system structure with the WECS, a microgrid with two DGs and its local load and utility is shown in Fig. 1. As shown in Fig. 1 that PMSG is connected through a full scale 
voltage converter. The wind side converter is used to control the active power flow from the PMSG, while grid side converter holds the DC capacitor voltage $V_{d c}$ constant. The WECS is connected with infinite bus through a transformer. In the microgrid, DG-1 is a microturbine and DG-2 is a diesel generator. Real and reactive powers supplied by the DGs are denoted by $P_{1}, Q_{1}$ and $P_{2}, Q_{2}$. The WECS supplies power $P_{W M}$ to microgrid and the rest of the power $\left(P_{g}\right)$ is supplied to the infinite bus. The microgrid is connected with Utility and WECS through another back-to-back converter VSC-1 and VSC-2.

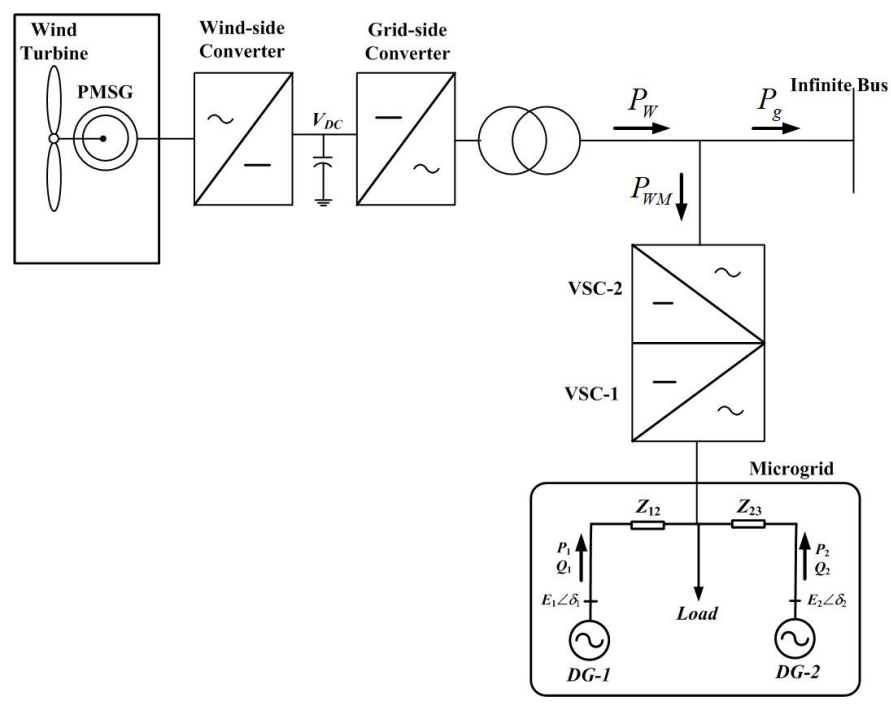

Fig. 1. System Structure.

\section{WIND TURBINE WITH PMSG MODELLING AND CONTROL}

\section{A. Wind Turbine with PMSG Model}

The wind power that is captured by the blade and converted into mechanical power can be calculated by

$$
P_{M}=\frac{1}{2} \rho A v_{\omega}^{3} C_{p}
$$

where $\rho$ is the air density, $A$ is the cross-sectional area through which the wind passes, $v_{\omega}$ is the wind speed and $C_{p}$ is the power coefficient of the blade. The parameters of the wind turbine used in this paper are given in Table I in the appendix. The power coefficient $C_{p}$ is calculated from [10]

$$
C_{p}=0.5176\left(\frac{116}{\lambda_{i}}-0.4 \beta-5\right) e^{\frac{-21}{\lambda_{i}}}+0.0068 \lambda
$$

where $\beta$ is the pitch angle, $\lambda$ is the tip speed ratio (the blade tip moving speed divided by the wind speed), and $\lambda_{l}$ is given by

$$
\frac{1}{\lambda_{i}}=\frac{1}{\lambda+0.08 \beta}-\frac{0.035}{\beta^{3}+1}
$$

The wind turbine operates at the generator control mode when the wind speed is below the rated wind speed, and works under the pitch control when the wind speed exceeds the rated value. For the generator control mode, an MPPT control method is applied in this paper to capture the maximum power from the wind. As for the pitch angle control, a PI controller is employed, which is shown in Fig. 2 [11].

The input is the error of the measured wind turbine output power $P_{m}$ and the rated power $P_{r e f}$. The rate limiter and the hard limiter are to limit the rate of change and the boundary values of the pitch angle. The parameters of the PI controller, the rate limiter and the hard limiter are listed in Table II in the appendix.

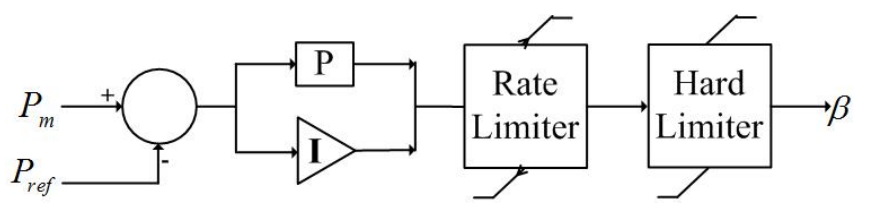

Fig. 2. Pitch control.

According to the pitch control scheme, when $P_{m}$ is equal to or smaller than $P_{\text {ref }}$, the error is negative and $\beta$ can be kept at its optimal value to capture the maximum power available from the wind based on the MPPT control. If $P_{m}$ is bigger than $P_{\text {ref }}$, the error is positive and $\beta$ will regulate to limit the power output of the wind turbine to prevent the power from exceeding the designed capacity. If $P_{m}$ is too big implying that the wind speed is over the designed cut-out speed, $\beta$ will change to pitch out of the blade and the wind turbine will be shut down.

The PMSG used in this paper is the model package which is available in PSCAD [12]. It is a non-salient synchronous generator. There is no gearbox between the wind turbine and the generator. The parameters of the PMSG are given in Table $\mathrm{I}$ in the appendix.

\section{B. PMSG Operation with Varied Wind Speeds}

To verify the modelling and control strategy applied in this paper, we write the varied wind speeds through the following equations:

$$
\begin{aligned}
& v_{w}= \begin{cases}v_{m} & t<t_{1} \\
v_{m}+k \cdot\left(t-t_{1}\right) & t_{1}<t<t_{2} \\
v_{m}+k \cdot\left(t_{2}-t_{1}\right) & t>t_{2}\end{cases} \\
& v_{E S}=k \cdot\left(t_{2}-t_{1}\right)
\end{aligned}
$$

where $v_{w}$ is the wind speed available to the turbine, $v_{m}$ is the mean wind speed, $k$ is the ramp change in the wind speed, $t_{1}$ and $t_{2}$ are the starting and ending time respectively of the wind speed ramping duration, $v_{E S}$ is the external wind speed of the wind source.

With the PMSG connecting directly to the load without converters, we cannot get a constant output voltage when the wind speed changes. The most commonly used full capacitor converters applied in PMSGs are the back-to-back VSCs. Here converters with Insulated Gate Bipolar Transistors (IGBTs) are used to get the maximum power from wind energy and to keep the DC voltage at a constant value. 


\section{PMSG With Voltage Source CONVERTERS}

The schematic diagram of the PMSG with voltage source converters based on $[4,12,13]$ is shown in Fig. 3. The wind kinetic energy is converted to mechanical energy by the wind turbine and then transmitted to the generator through the drive train. The PMSG is connected to the WSC directly without a gearbox. The DC power after the WSC is converted to $\mathrm{AC}$ power by the GSC and then connected to the $\mathrm{AC}$ grid through a transformer and a short line. The grid is modelled as an ideal voltage source (infinite bus). The parameters of the DC line, the transformer and the infinite bus are listed in Table III in the appendix.

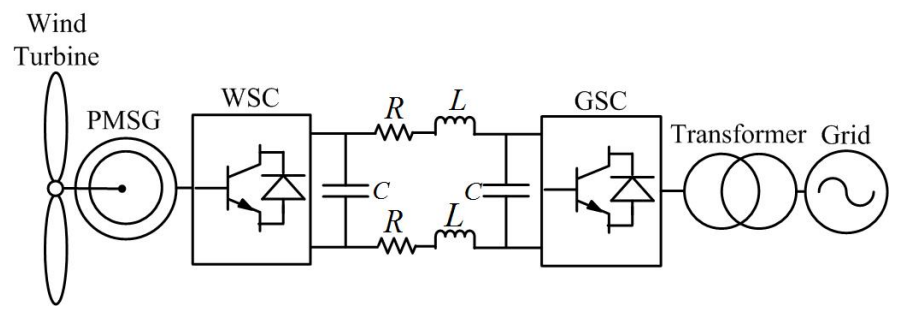

Fig. 3. Schematic diagram of PMSG with back-to-back converter

In general, for PMSG based WECS, in the control scheme, the wind-side converter controls the active power through MPPT, while the grid-side converter controls the DC voltage and reactive power to the grid [4]. The same control method is applied in this paper.

\section{A. Wind-side Converter Control with MPPT}

To extract the maximum power from the wind energy, turbine blades should change their speed as the wind speed changes. Reference [4] gives out three methods to realize the MPPT control. Based on the PMSG model in this paper, to control the generator power, we have applied a similar method to Optimal Torque Control (OTC), which is named as the Optimal Power Control (OPC).

The principle of the OTC is that the wind turbine mechanical torque $T$ and the turbine speed $\omega$ have the following relationship at MPPT control

$$
T \propto \omega^{2}
$$

Assuming that the generator power is denoted by $P$, this is given in OPC as

$$
P \propto \omega^{3}
$$

It should be noted that the values of the turbine speed and the generator speed are equal considering that the PMSG model is direct drive. Fig. 4 shows the schematic diagram of the MPPT control through VSC rectifier, where $K_{\text {opt }}$ is the coefficient for the optimal power that can be calculated according to the generator rated parameters, $P_{r e f}$ is the power reference, $v_{g}$ and $i_{g}$ are the gird voltage and current respectively.

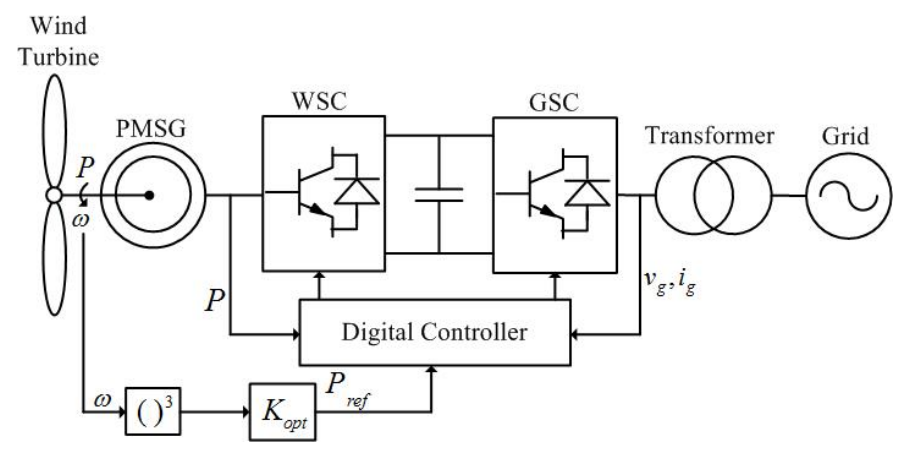

Fig. 4. Schematic diagram of MPPT control

The well-known Sinusoidal Pulse Width Modulation (SPWM) control technique is applied for the wind-side converter. Through the MPPT method, the $d q$-axis currents can be calculated. The $d q$-axis voltages can then be obtained by the PI controller using the current differences [4]. In this way, the reference voltages for the PWM control is obtained by transferring the voltage values of the $d q$-axis to the $a b c$ frame, so the generator power is controlled by the VSC rectifier.

\section{B. Inveter Control}

The Space Vector PWM (SVPWM) control [15-16] is applied in the inverter control to convert the DC power to $\mathrm{AC}$ power. The switches of the three-phase, two-level inverter are named as illustrated in Fig. 5.

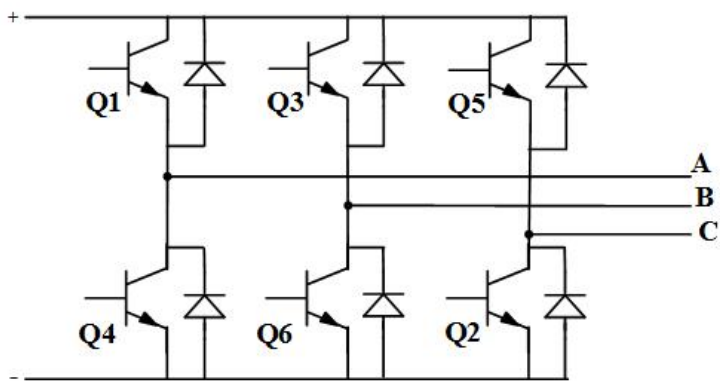

Fig. 5. Inverter topology

Assume that the inverter terminal voltage is 1 when the upper switch is on and 0 when the lower switch is on, there will be 8 switching states, as shown in Fig. 6 . In this figure, the reference voltage vector $V_{\text {ref }}$ rotates through the space so $V_{\text {ref }}$ can be synthetized by different base vectors $\left(V_{l}\right.$ to $\left.V_{6}\right)$, which means that different sets of switches can be turned on and off.

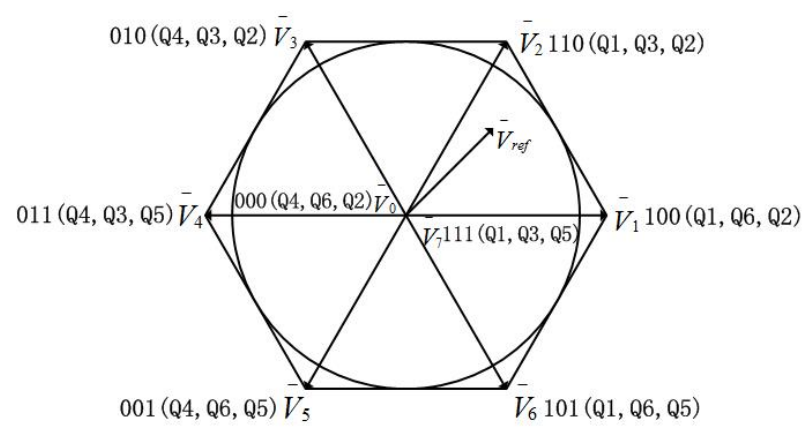

Fig. 6. Space vector locations for the two-level inverter 
By using the SVPWM technique for the proposed model in this paper, the DC voltage of the synchronous generation WECS is controlled at $4.5 \mathrm{kV}$.

\section{INTREGRATION OF WECS WITH MICROGRID}

In a microgrid, DGs are assumed to be operating in frequency droop control to share the real power amongst themselves according to their ratings. The droop characteristics are given by [17]

$$
f=f_{r}+m \times\left(0.5 \times P_{r}-P\right)
$$

where $f$ and $f_{r}$ respectively are the instantaneous and rated frequency of the DGs. Whereas, rated and measured real powers are presented by $P_{r}$ and $P$ respectively. The droop coefficient is denoted by $m$, which is calculated according to the DGs ratings. Note that with the droop equation given in (9), the microgrid frequency will be $50 \mathrm{~Hz}$ when the DGs supply half their rated power.

The microgrid frequency differs from $50 \mathrm{~Hz}$ depending on load. However, the frequency should not deviate more than \pm $0.3 \mathrm{~Hz}$. On the other hand, the WECS and utility operate at a fixed frequency of $50 \mathrm{~Hz}$. Therefore, to integrate WECS with microgrid, a back-to-back converter is used such that frequency isolation can be provided.

\section{A. BACK-TO-BACK CONVERTER}

The back-to-back converters also control power flow from the utility system to the microgrid. This contains two VSCs that are connected to a DC link capacitor. VSC-1 controls the voltage at the point of common coupling with the microgrid such that a fixed amount of power is drawn from the WECSutility system. The purpose of VSC-2 is to hold the DC link voltage constant by the required amount of power from the WECS-utility system. As mentioned before, the microgrid can operate at the frequency different from $50 \mathrm{~Hz}$. Therefore, PLL is used to synchronize the VSC-1 with microgrid in the same manner as discussed in [9]. As shown in Fig. 1, the back-toback converters facilitate the power $P_{W M}$ flow the WECS and utility to the microgrid.

\section{SimUlation STUdies}

Simulation studies are carried out in PSCAD/EMTDC in which different patterns of wind speed and local load of microgrid are considered. In the microgrid, the DGs are considered as inertial and non-inertial sources to supply its local load. The droop coefficients are chosen such that DGs can share the power according to their rating. The parameters of droop control and rating of DGs are given in Table IV. The results are discussed below.

\section{A. Case 1: WECS at constant speed with MG and Utility}

For this case, it has been assumed that the microgrid and the WECS-utility systems are operating in their steady state, when they are connected together at 2 s. $P_{W M}$ is chosen as 300 $\mathrm{kW}$. The real power flowing through the various parts of the system is shown in Fig. 7. It can be seen from this figure that the load power $P_{L}$ remains constant after the connection, while the power supplied by the DGs reduces proportionally, i.e., in the ratio 1:2. The frequencies of the DGs are shown in Fig. 8. We can see from this figure that, as $P_{W M}$ starts flowing to the microgrid, the DGs frequencies start increasing. They settle at a value that is higher than $50 \mathrm{~Hz}$, indicating that the DGs are supplying less than half of their rated power.

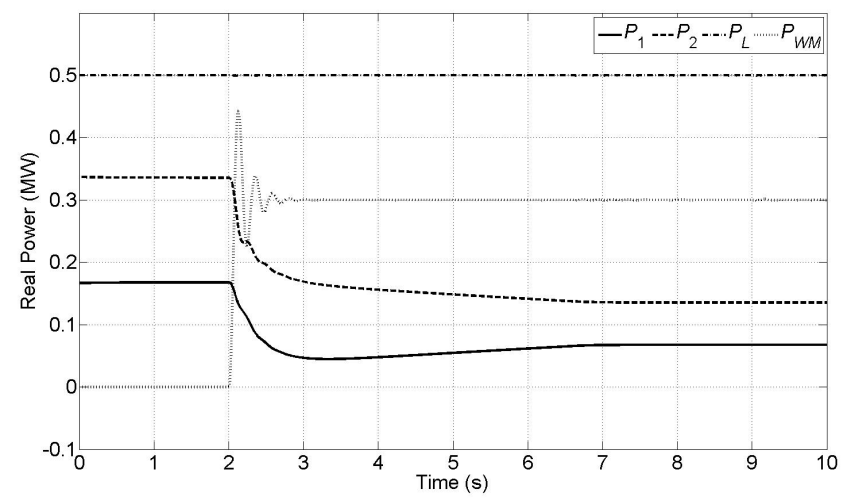

Fig. 7. Real power sharing amongst DGs with WECS power towards microgrid in Case 1.

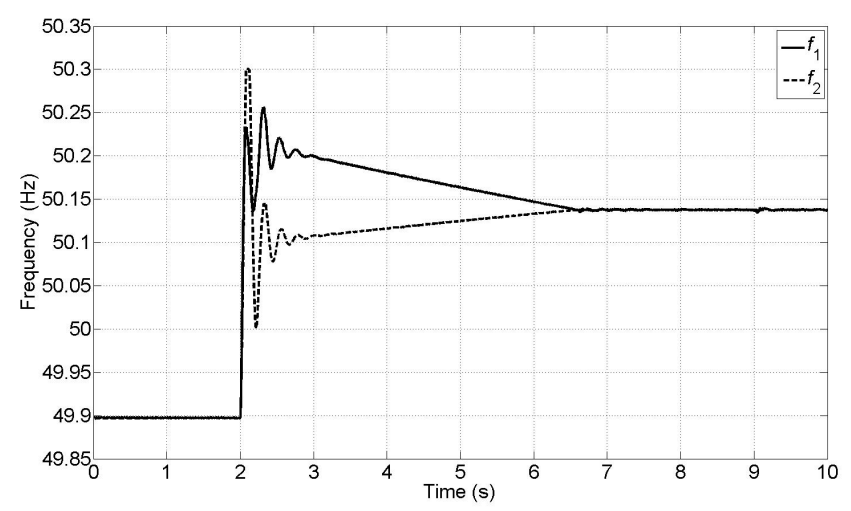

Fig. 8. Frequencies of DGs in Case 1.

\section{B. Case 2: WECS at variable speed with $M G$ and Utility}

In this case, the wind speed of the WECS is varied. Initially the wind speed is constant at $10 \mathrm{~m} / \mathrm{s}$. Then $10 \mathrm{~s}$, it starts ramping up to $12 \mathrm{~m} / \mathrm{s}$ till $12 \mathrm{~s}$. This is shown in Fig. 9. As a consequence, the output power of WECS changes as shown in Fig. 10. Once wind speed increases the output power of WECS $\mathrm{P}_{W}$ and the power flowing towards the infinite bus $P_{g}$ also increase. However since the power $P_{W M}$ is regulated to a fixed set point by the back-to-back converters, it remains constant despite increase in the wind speed.

\section{Case 3: Load variation in MG with WECS}

With the entire system operating in the steady state, the microgrid local load is increased by $100 \mathrm{~kW}$. The results are shown in Figs. 11 and 12. It can be seen from Fig. 11 that the power $P_{W M}$ remains constant, while the power supplied by the DGs $\left(P_{1}\right.$ and $\left.P_{2}\right)$ is raised in accordance with their ratings to meet the increased load demand. The frequencies of DGs are reduced as power supply from DGs increases. These are shown in Fig. 12. 


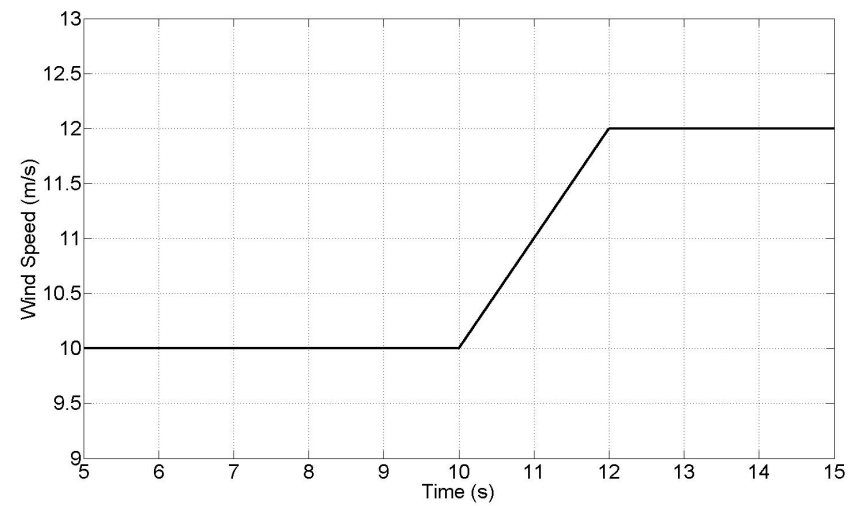

Fig. 9. Wind speed in Case 2.

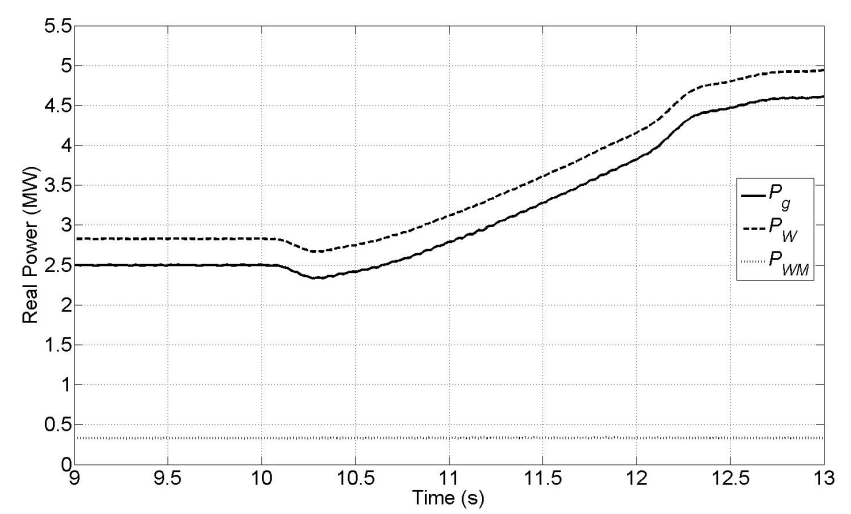

Fig. 10. Power flow from the WECS to the utility and microgrid in Case 2.

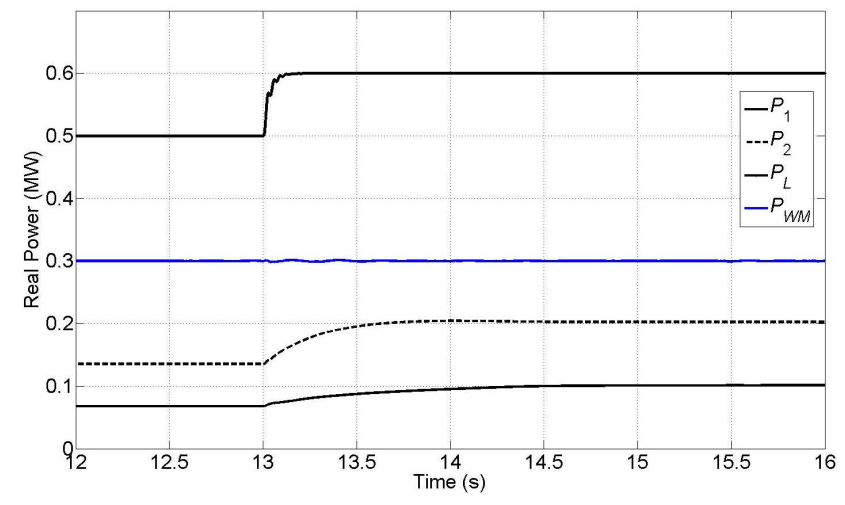

Fig. 11. Real power sharing amongst DGs with WECS power towards microgrid in Case 3.

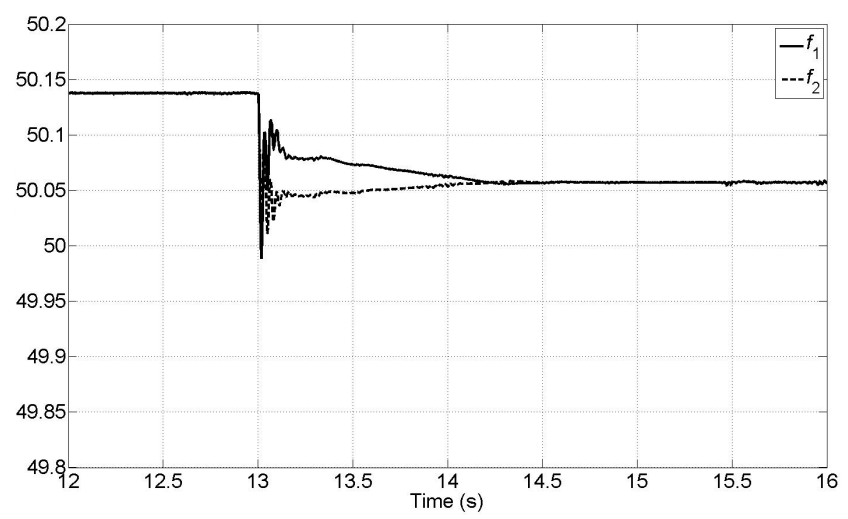

Fig. 12. Frequencies of DGs in Case 3.

\section{Case 4: Tripping of WECS}

Usually wind turbines operate when the wind speed exceeds $4-5 \mathrm{~m} / \mathrm{s}$, and is shut off at speeds exceeding 25 to 30 $\mathrm{m} / \mathrm{s}$ [19]. If wind speed is less than the cut in speed or higher than the cut off speed in that case WECS will disconnect from the utility. For this case, the wind speed is reduced from 10 $\mathrm{m} / \mathrm{s}$ to the cut in speed as shown in Fig. 13. Therefore, the power $P_{W}$ from WECS becomes zero after $17 \mathrm{~s}$. However, power $P_{W M}$ remains constant and this power now flows from the utility. The power $P_{g}, P_{W}$ and $P_{W M}$ are shown in Fig. 14. It can be seen that as $P_{W}$ drops $P_{g}$ also drops. Once $P_{W}$ becomes zero $P_{g}$ becomes negative and equal to $P_{W M}$ since power flow from the utility is now reversed towards the microgrid.

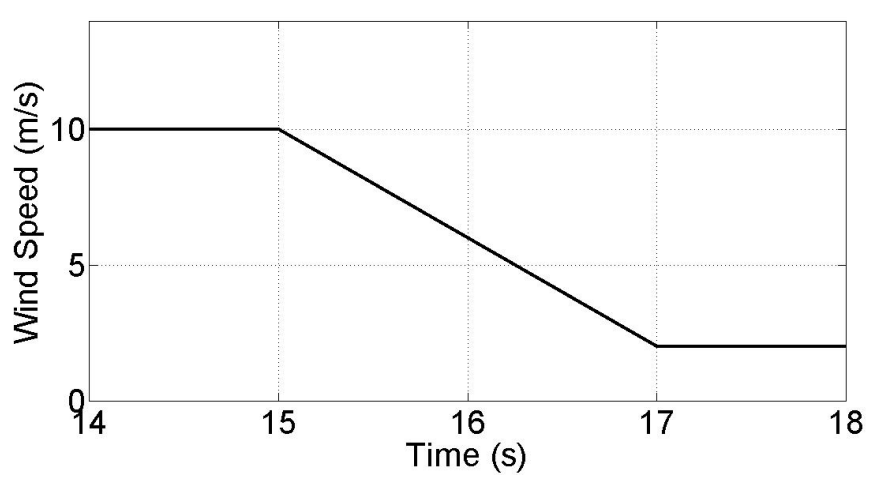

Fig. 13. Wind speed in Case 4.

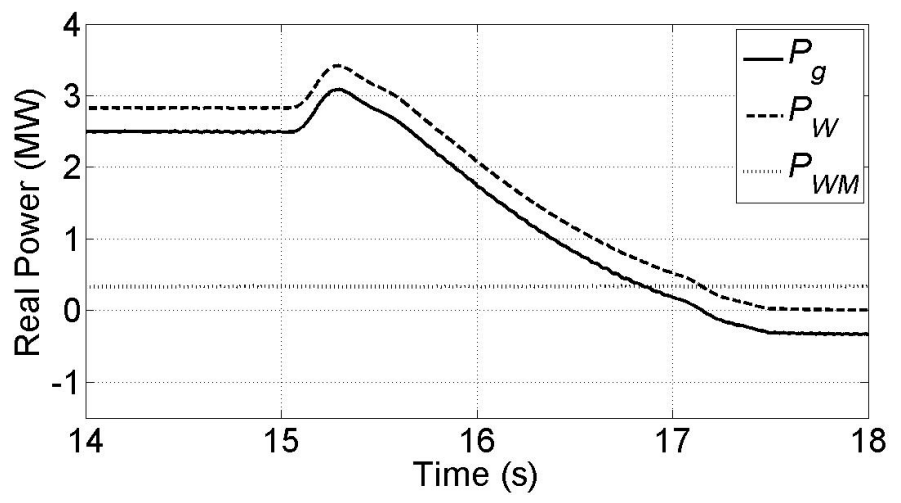

Fig. 14. Power flow in system in Case 4.

\section{CONCLUSIONS}

In this paper, an integration strategy of WECS with microgrid and utility is proposed. For MPPT control Optimal Power Control (OPC) scheme is used to draw maximum possible power from the wind energy. Variable wind speed is considered and a wind turbine tripping case is also studied. A back-to-back converter is used to control the constant amount of power from WECS and utility towards microgrid. The developed control strategy is validated through computer simulation using PSCAD/EMTDC. 


\section{ACKNOWLEDGEMENT}

The authors thank the Australian Research Council (ARC) for the financial support for this project through the ARC Discovery Grant DP110104554.

\section{REFERENCES}

[1] Y. Dong-Hee, S. ByoungYoon, S. Chong Suk, L. Hansang, and J. Gilsoo, "Study on Jeju Island power system considering multiple HVDC," in Proc. IEEE Power and Energy Society General Meeting, 2010.

[2] Y. Dong-Hee, S. Hwachang, J. Gilsoo, and J. Sung-Kwan, "Smart operation of HVDC systems for large penetration of wind energy rsources," IEEE Trans. Smart Grid, vol. 4, pp. 359-366, 2013.

[3] S. M. Muyeen, R. Takahashi, and J. Tamura, "Operation and control of HVDC-connected offshore wind farm," IEEE Trans. Sustain. Energy, vol. 1, no. 1, pp. 30-37, 2010.

[4] B. Wu, Y. Lang, N. Zargari and S. Kouro, Proc. Power Conversion and Control of Wind Energy Systems, 2011.

[5] P. Vas, Electrical Machines and Drives- A Space Vector Theory Approach, New York: Oxford Univ. Press, 1992.

[6] T. J. E. Miller, Brushless Permanet- Magnet and Reluctance Motor Drives, New York: Oxford Univ. Press, 1989.

[7] Y. Zhao, C. Wei, Z. Zhang, and W. Qiao, “A review on position/speed sensorless control for permanent-magnet synchronous machine-based wind energy conversion systems," IEEE Journal of Emerging and Slected Topics in Power Electronics, vol. 1, no. 4, pp: 203-216, 2013.

[8] J. A. Baroudi, V. Dinavahi, and A. M. Knight, "A review of power converter topologies for wind generators," Renewable Energy, vol. 32, , pp. 2369-2385, 2007.

[9] M. Goyal and A. Ghosh, "A phase-locked-loop design for the smooth operation of a hybrid microgrid," Australian Universities Power Engineering Conference, AUPEC, pp. 1-6, 2013.

[10] A. A. Jadallah, D. Y. Mahmood, and Z. A. Abdulqader, "Optimal performance of horizontal axis wind turbine for low wind speed regime," International Journal of Multidisciplinary and Current Research, vol.2, pp. 159-164, 2014.

[11] K. Kurohane, T. Senjyu, A. Yona, N. Urasaki, T. Goya, and T. Funabashi, "A hybrid smart AC/DC power system," IEEE Trans. Smart Grid, vol. 1, no. 2, pp. 199-204, 2010.

[12] "PSCAD/EMTDC Manual," Manitoba HVDC Research Center, Apr. 2005.

[13] M. Yin, G. Li, and M. Zhou, "Modeling of the wind turbine with a permanent magnetic synchronous generator for integration," IEEE Trans. Power Electron., vol. 6, no. 25, pp. 903-911, 2007.

[14] W. Hu, Z. Chen, Y. Wang, and Z. Wang, "Wind power fluctuations mitigation by DC-link voltage control of variable speed wind turbines," IEEE Trans. Power Electron., vol. 10, no. 4, pp. 108-116, 2008.

[15] H. Zeng and H. Nian, "Novel topology and control strategy of HVDC grid connection for open winding PMSG based wind power generation system," Journal of International Conference on Electrical Machines and Systems, Calgary, vol. 3, no. 2, pp. 215-221, 2014.

[16] P. Tripura, Y. S. K. Babu, Y. R. Tagore, "Space vector pulse width modulation schmes for two-level voltage source inverter," ACEEE Int. J. on Control System and Instrument, vol. 2, no. 3, pp. 34-38, 2011.

[17] P. Kundur, Power System Stability and Control, McGraw-Hill, New York, 1994.

[18] R. Majumder, A. Ghosh, G. Ledwich and F. Zare, "Power management and power flow control with back-to-back converters in a utility connected microgrid," IEEE Trans. on Power Systems, vol. 25, no. 2, pp. 821-834, 2010.

[19] M. R . Patel, Wind and Solar Power Systems, USA: CRC Press, 1999, pp. $124-130$.

\section{APPENDIX}

TABLE I. WIND TURBINE AND PMSG PARAMETERS

\begin{tabular}{|c|c|}
\hline Parameters Names & Parameter Values \\
\hline Rotor radius & $58 \mathrm{~cm}$ \\
\hline Air density & $1.225 \mathrm{~kg} / \mathrm{m}^{3}$ \\
\hline Rated wind speed & $12 \mathrm{~m} / \mathrm{s}$ \\
\hline Rated mechanical power & $5.0 \mathrm{MW}$ \\
\hline Rated apparent power & $5.217 \mathrm{MVA}$ \\
\hline Rated line-to-line voltage & $3 \mathrm{kV}$ \\
\hline Rated frequency & $10 \mathrm{~Hz}$ \\
\hline Number of pole pairs & 49 \\
\hline
\end{tabular}

TABLE II. Pitch Control Parameters

\begin{tabular}{|c|c|}
\hline Parameters Names & Parameter Values \\
\hline Proportional gain & 100 \\
\hline Integral time constant & $0.001 \mathrm{~s}$ \\
\hline Maximum increase rate & $1000[1 / \mathrm{s}]$ \\
\hline Maximum decrease rate & $1000[1 / \mathrm{s}]$ \\
\hline Upper limit & $60[\mathrm{deg}]$ \\
\hline Lower limit & 0 \\
\hline
\end{tabular}

TABLE III. RELATED PARAMETERS OF BACK-TO-BACK CONVERTER

\begin{tabular}{|c|c|}
\hline Parameter Names & Parameter Values \\
\hline DC line resistor & $0.05 \mathrm{ohm}$ \\
\hline DC line inductance & $0.002 \mathrm{H}$ \\
\hline Transformer capacity & $20 \mathrm{MVA}$ \\
\hline Transformer line voltages & $3 \mathrm{kV} / 35 \mathrm{kV}$ \\
\hline Infinit bus voltage & $35 \mathrm{kV}$ \\
\hline
\end{tabular}

TABLE IV. PARAmeters OF THE DGs CONNECTED TO THE MiCrogrid

\begin{tabular}{|c|c|}
\hline System Quantities & Values \\
\hline $\mathrm{DG}_{1}$ Feeder impedance & $R_{f 1}=3.025 \Omega, L_{f 1}=57.8 \mathrm{mH}$ \\
\hline $\mathrm{DG}_{2}$ Feeder impedance & $R_{f 2}=3.025 \Omega, L_{f 2}=57.8 \mathrm{mH}$ \\
\hline $\mathrm{DG}_{3}$ Feeder impedance & $R_{f 3}=3.025 \Omega, L_{f 3}=57.8 \mathrm{mH}$ \\
\hline DG Rated Power & MT: $250 \mathrm{~kW}$, DGEN: $500 \mathrm{~kW}$ \\
\hline \multicolumn{2}{|c|}{ Droop Coefficient (Frequency-Voltage) } \\
\hline$m_{1}$ & $0.015 \mathrm{rad} / \mathrm{MWs}$ \\
\hline$m_{2}$ & $0.0075 \mathrm{rad} / \mathrm{kWs}$ \\
\hline$n_{1}$ & $0.04 \mathrm{kV} / \mathrm{MVAr}$ \\
\hline$n_{2}$ & $0.02 \mathrm{kV} / \mathrm{MVAr}$ \\
\hline
\end{tabular}

